\title{
Chapter 24 \\ Molecular Interactions of Peptide Encapsulated Calcium Phosphate Delivery Vehicle at Enamel Surfaces
}

\author{
Noorjahan Laila Huq, Keith John Cross, Helen Myroforidis, \\ David Phillip Stanton, Yu-Yen Chen, Brent Robert Ward, \\ and Eric Charles Reynolds
}

\begin{abstract}
Phosphorylated peptides derived from milk caseins, known as casein phosphopeptides (CPP), self-assemble and encapsulate the calcium and phosphate mineral in the form of amorphous calcium phosphate (ACP), thus forming CPPACP nanocomplexes that are nontoxic and biocompatible. The biomedical application is the repair of tooth surfaces (enamel) at early stages of tooth decay. These nanocomplexes release calcium and phosphate ions to rebuild demineralised HA crystals in enamel subsurface lesions. The topical application of CPP-ACP at the tooth surface initiates a series of interactions at the enamel mineral hydroxyapatite surface and at the enamel salivary pellicle that are not well understood. In this study, we have shown that the $\beta$-casein (1-25) peptide binds reversibly to $\mathrm{Ca}^{2+}, \mathrm{Mg}^{2+}, \mathrm{Mn}^{2+}$, $\mathrm{La}^{2+}, \mathrm{Ni}^{2+}$, and $\mathrm{Cd}^{2+}$ metal ions. In contrast, binding to $\mathrm{Sn}^{2+}, \mathrm{Fe}^{2+}$, and $\mathrm{Fe}^{3+}$ ions resulted in ion-induced aggregation. The casein peptides as well as the mineral ions dissociate from the CPP-ACP complexes to adsorb to both the uncoated and salivacoated mineral surface with the mineralisation increasing monotonically with increasing $\mathrm{pH}$. Furthermore, SEM of the CPP-ACP revealed images of spherical particles surrounded by ACP mineral. In conclusion, the enamel remineralisation process involves an array of interactions between the peptide and mineral ions of the CPP-ACP delivery vehicle and the tooth enamel mineral with its salivary pellicle.
\end{abstract}

Keywords Enamel $\cdot$ CPP-ACP $\cdot$ Saliva $\cdot$ SEM $\cdot$ Hydroxyapatite $\cdot$ Mineralisation

\footnotetext{
N. L. Huq · K. J. Cross · H. Myroforidis · D. P. Stanton · Y.-Y. Chen · B. R. Ward

E. C. Reynolds $(\triangle)$

Oral Health Cooperative Research Centre, Melbourne Dental School, Bio21 Institute of

Molecular Science and Biotechnology, The University of Melbourne,

Melbourne, Victoria, Australia

e-mail: laila@unimelb.edu.au; keith.cross@unimelb.edu.au; dstanton@unimelb.edu.au;

yyyc@unimelb.edu.au; brentrw@unimelb.edu.au; e.reynolds@unimelb.edu.au
} 


\subsection{Introduction}

Dental caries is the destruction of tooth surfaces by acid generated by plaque odontopathogenic in a complex chemical process (Robinson et al. 2000). The reversibility of enamel hydroxyapatite mineral loss at early stages of dental caries has led to the development of various anticariogenic approaches to repair enamel lesions (Cochrane et al. 2010). One oral therapeutic consists of phosphorylated peptides derived from milk caseins, known as casein phosphopeptides (CPP) that selfassemble and encapsulate the calcium and phosphate mineral in the form of amorphous calcium phosphate (ACP) (Reynolds et al. 1995).

At the tooth surface, the mechanism of the remineralisation process by CPP-ACP including the changes in the chemical equilibria of the complexes and the enamel lesions is unclear. Above the enamel hydroxyapatite are further zones of chemical complexity, including the layer of salivary proteins known as the acquired enamel pellicle and the outermost layer of oral biofilm. Our long-term goal has been to study the molecular interactions between CPP-ACP complexes (Cross et al. 2016) and enamel hydroxyapatite, salivary proteins (Huq et al. 2016), and the oral biofilm (Dashper et al. 2016) that would occur during topical application of CPP-ACP in the oral cavity. In this study, we investigate the interactions between peptide and crystalline and non-crystalline mineral components during the remineralisation process by the peptide encapsulated delivery vehicle CPP-ACP.

\subsection{Materials and Methods}

The sequences of four bovine casein-derived tryptic phosphopeptides containing the cluster sequence motif $-(\operatorname{Ser}(P)-)_{3}(\mathrm{Glu}-)_{2}$ are shown in Fig. 24.1. The two dominant, self-assembling peptides are $\beta-\mathrm{CN}(1-25)$ and $\alpha_{\mathrm{S} 1}-\mathrm{CN}(59-79)$ forming $20-30 \%$ by mass of the total CPP (Fig. 24.1).

[1] $\quad \operatorname{Arg}^{1}$-Glu-Leu-Glu-Glu-Leu-Asn-Val-Pro-Gly-Glu-Ile-Val-Glu-Ser $(P)$-Leu$(\operatorname{Ser}(P)-)_{3}(\text { Glu- })_{2}-$ Ser-Ile-Thr-Arg ${ }^{25} \quad \beta-\mathrm{CN}(1-25)$

[2] Gln ${ }^{59}$-Met-Glu-Ala-Glu-Ser $(P)-$ Ile- $(\underline{\operatorname{Ser}(P)})_{3}{ }_{3}(\mathrm{Glu}-)_{2}-$ Ile-Val-Pro-Asn-Ser $(P)-$ ValGlu-Gln-Lys ${ }^{79} \quad \alpha_{\mathrm{S} 1}-\mathrm{CN}(59-79)$

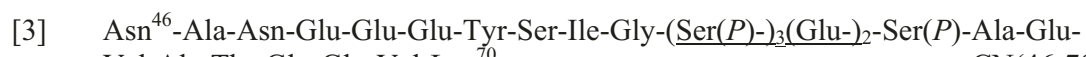
Val-Ala-Thr-Glu-Glu-Val-Lys ${ }^{70} \quad \alpha_{\mathrm{S} 2}-\mathrm{CN}(46-70)$

[4] Lys ${ }^{1}$-Asn-Thr-Met-Glu-His-Val-( $\underline{\operatorname{Ser}(P)-)_{3}(G l u-)_{2}-S e r-I l e-I l e-S e r}(P)-G l n-G l u-T h r-$ Tyr-Lys ${ }^{21}$ $\alpha_{\mathrm{S} 2}-\mathrm{CN}(1-21)$

Fig. 24.1 The sequences of the four major casein tryptic phosphopeptides are depicted using the three-letter code with the motif $-(\operatorname{Ser}(P)-) 3(\mathrm{Glu}-) 2$ underlined 


\subsubsection{Adsorption Studies}

An assay was developed to determine the binding of the CPP-ACP components 1 and 2 (Fig. 24.1) to enamel using an in vitro model with synthetic HA used as a substitute for dental enamel (Huq et al. 2016). The standard curve was derived from peak heights of the RP-HPLC profiles of purified peptides with concentrations ranging from 10 to $1000 \mu \mathrm{g} / \mathrm{ml}$ in $25 \mathrm{mM} \mathrm{NaCl}$ and $25 \mathrm{mM}$ imidazole buffer (pH 7). CPP of the same concentrations were incubated with end-over-end rotation for $1-4 \mathrm{~h}$ at $37{ }^{\circ} \mathrm{C}$ with $2 \mathrm{mg}$ of HA. The samples were centrifuged at $10,000 \mathrm{~g}$ for 15 min to pellet peptide bound to HA. The supernatants analysed by RP-HPLC provided the unbound peptide concentration. The partitioning of the free and peptide-bound ions was determined followed by measurements of calcium and phosphate ions (Cross et al. 2005). The saliva collection procedures and approval were as recently described (Huq et al. 2016).

\subsubsection{Chemical Equilibria Studies}

Test and control solutions were added to $2 \mathrm{mg}$ HA. After mixing thoroughly, the samples were incubated for $2 \mathrm{~h}$ at RT with end-over-end rotation. To remove the HA crystals, the samples were centrifuged at 10,000 g. The HA crystal-free supernatants as well as the original solutions were subjected to ion quantitation for the ions in both peptide-free and peptide-bound states. In a second study, the HA crystals were pre-equilibrated with water at the $3 \mathrm{pH}$ values. Following centrifugation, the calcium, phosphate, $\mathrm{H}^{+}$, and $\mathrm{OH}^{-}$ions released from the uncoated and saliva-coated HA crystals into the supernatants were measured. These supernatants were used to prepare the $0.2 \% \mathrm{CPP}-\mathrm{ACP}$ solutions. The partitioning of the ions associated with the peptide complexes and those free in solution was determined. These supernatants were then added to the pre-equilibrated HA. The concentrations of total, free, and CPP-bound calcium and phosphate ions and $\mathrm{pH}$ values of the $0.2 \% \mathrm{CPP}-\mathrm{ACP}$ solutions prepared at $\mathrm{pH} 5.5,7.0$, and 8.5 before and after incubation with crystallineuncoated HA and saliva-coated HA were measured.

The dissociation study was performed by adding varying amounts of HA to $1 \%$ CPP-ACP solution at $\mathrm{pH} 7$ and 5.5 and monitoring the supernatant profile by RP-HPLC.

\subsubsection{SEM Studies}

SEM of a 5\% CPP-ACP solution was performed using $1 \mathrm{kV}$ with $25 \mathrm{pA}$ current with a T1 detector in a Teneo VS instrument (FEI). Images at $10^{4}, 5 \times 10^{4}$, and $8 \times 10^{4}$ magnification were obtained. 


\subsection{Results}

\subsection{1 $\beta$-Casein (1-25) Peptide Demonstrates a Range of Interactions with Metal Ions}

We selected one of the principal components of CPP $\beta-\mathrm{CN}(1-25)(\mathbf{1}$, Fig. 24.1) for exposure to different metal ions to examine the recovery of peptide $\mathbf{1}$ by RP-HPLC at $\mathrm{pH}$ 2. A single peak with identical retention times on the chromatogram (Fig. 24.2) was observed for peptide 1 incubated with $\mathrm{Ca}^{2+}, \mathrm{Mg}^{2+}, \mathrm{Mn}^{2+}, \mathrm{La}^{2+}, \mathrm{Ni}^{2+}$, and $\mathrm{Cd}^{2+}$ ions. This was indicative of reversible ion binding. However, peptide $\mathbf{1}$ incubated with $\mathrm{Sn}^{2+}, \mathrm{Fe}^{2+}$, and $\mathrm{Fe}^{3+}$ ions, eluted as multiple broadened peaks indicative of ioninduced aggregation. This study confirms that $\beta-\mathrm{CN}(1-25)$ is capable of releasing the bound calcium ions at low $\mathrm{pH}$ without experiencing permanent aggregation.

\subsubsection{The Predominant Peptides of the CPP-ACP Complex Bind to Uncoated HA and Saliva-Coated HA}

To determine if the pure peptides derived from CPP directly interact with enamel, adsorption studies were performed with enamel substitute HA and saliva-coated HA. We analysed the individual adsorption patterns of the two peptides $\mathbf{1}$ and $\mathbf{2}$ with

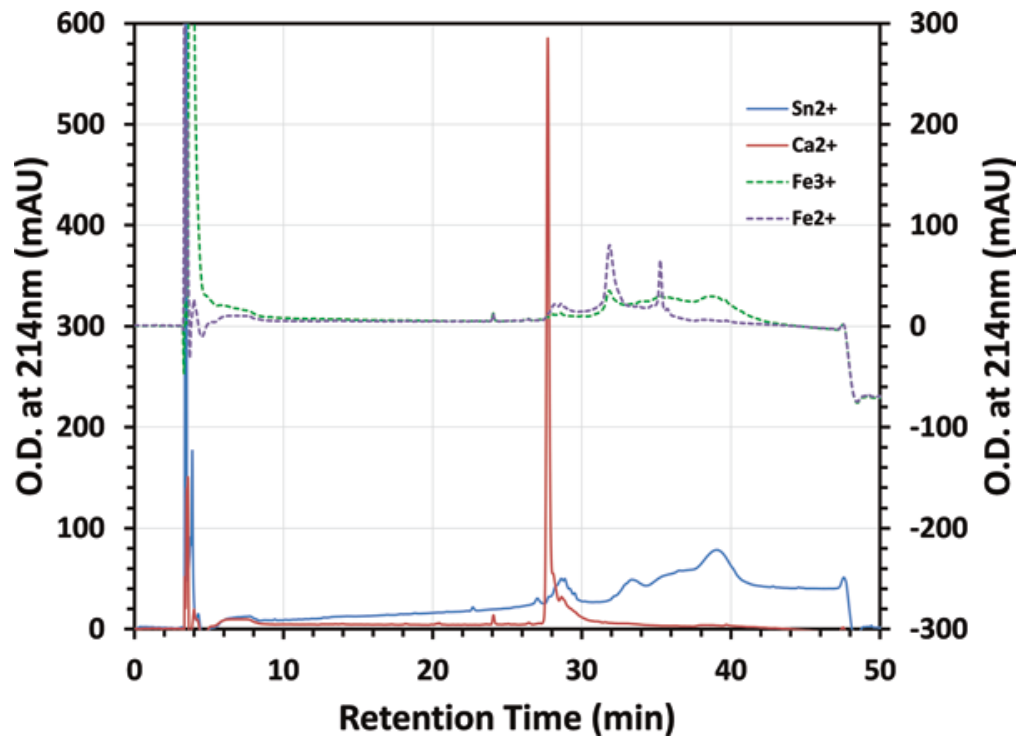

Fig. 24.2 RP-HPLC chromatogram depicting the recovery elution profiles of $\beta$-CN(1-25) incubated with $\mathrm{Ca}^{2+}, \mathrm{Sn}^{2+}, \mathrm{Fe}^{2+}$, and $\mathrm{Fe}^{3+}$ ions. The binding to $\mathrm{Ca}^{2+}$ ions by $\beta-\mathrm{CN}(1-25)$ is reversible; this is pivotal to the delivery of mineral by CPP-ACP to the enamel 


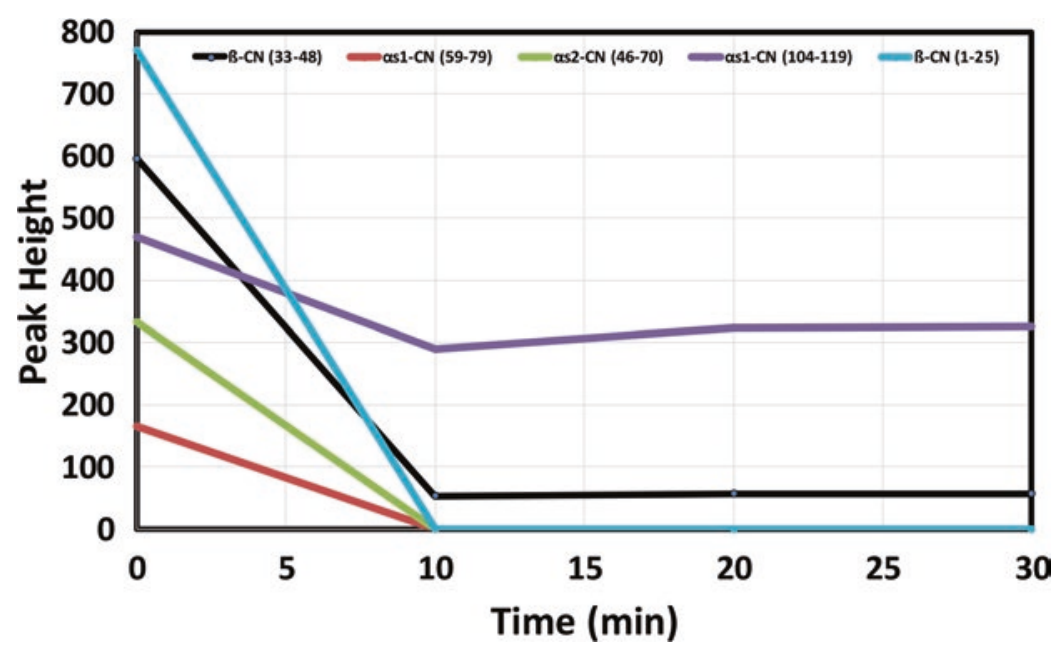

Fig. 24.3 RP-HPLC analysed loss of soluble casein phosphopeptides from CPP-ACP at pH 5.5 after addition of $\mathrm{HA}$ at $0 \mathrm{~min}$. The multi-phosphorylated [1-4] and mono-phosphorylated $\beta-\mathrm{CN}(33-48)$ peptides dissociate from the ACP to adsorb onto the crystalline HA

HA for Langmuir and Freund-type binding. Both peptides bound to HA surfaces according to a Langmuir-type adsorption model with peptide $\mathbf{1}(K=323 \pm 149 \mathrm{ml} /$ $\mu \mathrm{mol})$ having a higher affinity for HA than peptide $2(K=49 \pm 22 \mathrm{ml} / \mu \mathrm{mol})$. The adsorption profile of bound versus total showed an intermediate and final plateau indicating biphasic processes. At lower peptide concentrations, both peptide $\mathbf{1}$ $(K=463 \pm 200 \mathrm{ml} / \mu \mathrm{mol})$ and peptide $\mathbf{2}(K=194 \pm 122 \mathrm{ml} / \mu \mathrm{mol})$ had a greater affinity for the saliva-coated HA surface, than their respective affinities for an uncoated HA surface.

\subsubsection{Casein Peptides Dissociate from the CPP-ACP Complex to Bind to $\mathrm{HA}$}

The levels of soluble peptides from the CPP-ACP complexes at $\mathrm{pH}$ values 7.0 and 5.5 were monitored by RP-HPLC. Addition of HA caused a reduction of the soluble levels of peptides confirming that the multi-phosphorylated [1-4] and mono-phosphorylated peptide $\beta-\mathrm{CN}(33-48)$ dissociate from the ACP to adsorb onto HA. Figure 24.3 shows a representative time-dependent loss by $1 \% \mathrm{CPP}-\mathrm{ACP}$ at $\mathrm{pH} 5.5$. 


\subsubsection{The Chemical Equilibria of HA Surfaces Is Altered by the Addition of the Individual Peptides and Peptide- ACP Complexes}

The changes in chemical equilibria of HA surfaces were monitored during binding studies of crystalline HA exposed to pure peptides $\mathbf{1}$ or $\mathbf{2}$ (both without $\mathrm{Ca}^{2+}$ ) or $\beta$-CN(1-25)-ACP. The addition of HA to a solution of either of the two pure peptides 1 or 2 dissolved at $120 \mathrm{mg} / \mathrm{l}$ concentrations resulted in the post-addition measurement of $244 \pm 11 \mathrm{mM}$ and $124 \pm 5 \mathrm{mM}$ calcium, respectively, in the peptide solutions. This was interpreted as a peptide adsorption-mediated release of calcium ions from the crystalline HA into the solution (Misra 1997). In contrast, albumin $(120 \mathrm{mg} / \mathrm{l})$, used as a control, elicited a much lower adsorption-mediated release of $57 \pm 16 \mathrm{mM}$ calcium from HA. The initial $\mathrm{Ca}^{2+}$ concentration in a $240 \mathrm{mg} / \mathrm{l}$ solution of the $\beta-\mathrm{CN}(1-25)-\mathrm{ACP}$ complex was reduced after the addition of HA. The $\mathrm{Ca}^{2+}$ reduction from $355 \pm 67$ to $246 \pm 68 \mathrm{mM}$ was attributed to the calcium ions in the amorphous phase previously associated with the peptide $\mathbf{1}$ now binding to or precipitating with crystalline HA.

\subsubsection{The CPP-ACP Complexes Exhibit a pH-Dependent Release of Mineral Ions to Uncoated and Saliva-Coated HA Crystals}

The movement of calcium, phosphate, and hydroxyl ions to and from the uncoated and saliva-coated HA crystals during exposure to CPP-ACP was monitored during binding studies (Table 24.1). Table 24.1 shows a net loss of total calcium and phosphate ions from the CPP-ACP on binding to HA at $\mathrm{pH}$ 5.5, 7.0, and 8.5. This loss represented transfer of mineral from the amorphous phase of ACP to the crystalline HA. The net transfer was greatest at the highest $\mathrm{pH} 8.5$.

While the CPP-ACP complexes prepared at $\mathrm{pH} 9$ have most of the calcium and phosphate peptide bound, these complexes exist in solution in equilibrium with free ionic calcium and phosphate (Cross et al. 2005). The values in brackets indicate the proportion of free ions (Table 24.1). The proportion of mineral ions bound within complexes was reduced after incubation with both uncoated and saliva-coated HA. This was attributed to the dissociation of peptides from the complexes to remain free in solution and/or to adsorb to HA. The reductions in $\mathrm{pH}$ experienced by the CPP-ACP solutions following exposure to HA were attenuated in the presence of saliva-coated HA (Table 24.1).

The degree of saturation of the calcium phosphate solutions was calculated using the solubility products at $37{ }^{\circ} \mathrm{C}$ of hydroxyapatite (HA) $\left(\mathrm{K}_{\mathrm{sp}} \sim 10^{-117}\right)$, octacalcium phosphate (OCP) $\left(\mathrm{K}_{\mathrm{sp}} \sim 10^{-96}\right)$, dicalcium phosphate dihydrate (DCPD) $\left(\mathrm{K}_{\mathrm{sp}} \sim 10^{-6}\right)$, and ACP $\left(\mathrm{K}_{\mathrm{sp}} \sim 10^{-25}\right)$ (Cross et al. 2005). The calcium and phosphate ions were 
Table 24.1 Summary of the concentrations of total, free, and CPP-bound calcium and phosphate ions and $\mathrm{pH}$ values of the $0.2 \% \mathrm{CPP}-\mathrm{ACP}$ solutions prepared at $\mathrm{pH} 5.5,7.0$, and 8.5 before and after incubation with crystalline HA and saliva-coated HA

Solution [calcium] $(\mu \mathrm{M})$ before incubation with HA

\begin{tabular}{|c|c|c|c|}
\hline Total & $5261 \pm 32$ & $5285 \pm 17$ & $5225 \pm 9$ \\
\hline Free & $4801 \pm 50(91 \%)$ & $1847 \pm 49.12(35 \%)$ & $365 \pm 9(7 \%)$ \\
\hline CPP-bound & $460 \pm 60$ & $3438 \pm 52$ & $4860 \pm 13$ \\
\hline Initial pH & pH 5.55 & pH 6.99 & $\mathrm{pH} 8.5$ \\
\hline \multicolumn{4}{|c|}{ Supernatant after incubation with HA } \\
\hline Total & $5001 \pm 43$ & $4201 \pm 105$ & $3573 \pm 128$ \\
\hline Free & $4807 \pm 92(96 \%)$ & $2066 \pm 36(49 \%)$ & $524 \pm 35(15 \%)$ \\
\hline CPP-bound & $194 \pm 102$ & $2134 \pm 111$ & $3049 \pm 133$ \\
\hline HA-bound & $260 \pm 54$ & $1084 \pm 106$ & $1652 \pm 128$ \\
\hline Final $\mathrm{pH}$ & pH 5.32 & pH 6.85 & pH 7.89 \\
\hline
\end{tabular}

Supernatant after incubation with saliva-coated HA

\begin{tabular}{l|l|l|l}
\hline Total & $5042 \pm 51$ & $4224 \pm 51$ & $3620 \pm 52$ \\
\hline Free & $4908 \pm 169(97 \%)$ & $2058 \pm 50(49 \%)$ & $527 \pm 21(15 \%)$ \\
\hline CPP-bound & $134 \pm 177$ & $2166 \pm 72$ & $3093 \pm 56$ \\
\hline HA-bound & $219 \pm 60$ & $1061 \pm 54$ & $1605 \pm 53$ \\
\hline Final pH & pH 5.55 & pH 6.88 & pH 8.04
\end{tabular}

Solution [phosphate] $(\mu \mathrm{M})$ before incubation with HA

\begin{tabular}{l|l|l|l}
\hline Total & $3699 \pm 6$ & $3744 \pm 21$ & $3739 \pm 16$ \\
\hline Free & $3354 \pm 184(91 \%)$ & $1420 \pm 73(38 \%)$ & $386 \pm 3(10 \%)$ \\
\hline CPP-bound & $346 \pm 185$ & $2324 \pm 76$ & $3353 \pm 15$ \\
\hline Initial pH & pH 5.55 & pH 6.99 & pH 8.5
\end{tabular}

Supernatant after incubation with HA

\begin{tabular}{l|l|l|l}
\hline Total & $3461 \pm 35$ & $2930 \pm 42$ & $2485 \pm 89$ \\
\hline Free & $3223 \pm 175(93 \%)$ & $1599 \pm 44(55 \%)$ & $627 \pm 29(25 \%)$ \\
\hline CPP-bound & $238 \pm 179$ & $1331 \pm 61$ & $1858 \pm 94$ \\
\hline HA-bound & $238 \pm 36$ & $814 \pm 47$ & $1254 \pm 90$ \\
\hline Final pH & pH 5.32 & pH 6.85 & pH 7.89 \\
\hline
\end{tabular}

Supernatant after incubation with saliva-coated HA

\begin{tabular}{l|l|l|l}
\hline Total & $3427 \pm 37$ & $2757 \pm 53$ & $2443 \pm 50$ \\
\hline Free & $3191 \pm 50(93 \%)$ & $1475 \pm 59(54 \%)$ & $518 \pm 41(21 \%)$ \\
\hline CPP-bound & $236 \pm 62$ & $1281 \pm 79$ & $1925 \pm 65$ \\
\hline HA-bound & $272 \pm 37$ & $987 \pm 57$ & $1296 \pm 53$ \\
\hline Final pH & pH 5.55 & pH 6.88 & pH 8.04 \\
\hline
\end{tabular}

saturated with respect to the HA phase for both total and unbound fractions at all $\mathrm{pH}$ values (Table 24.2). In summary, these studies have confirmed that mineral ions are released from CPP-ACP that adsorb onto the crystalline HA and that mineralisation increases monotonically with increasing $\mathrm{pH}$. 
Table 24.2 Degree of saturation of calcium phosphate solutions before and after incubation of $0.2 \% \mathrm{CPP}-\mathrm{ACP}$ at different $\mathrm{pH}$ with $\mathrm{HA}$ or saliva-coated HA

\begin{tabular}{l|l|r|l|l|r|l|l}
\hline A & Total fraction: total calcium and phosphate in $0.2 \%$ CPP-ACP \\
\hline & \multicolumn{7}{|l}{ Mineral } \\
\hline Original pH & Final pH & HA & DCPD & TCP & OCP & Acid ACP & Basic ACP \\
\hline pH 5.55 & pH 5.55 & $\mathbf{4 . 0 5}$ & 0.92 & 0.465 & $\mathbf{1 . 4 1}$ & 0.21 & 0.07 \\
\hline pH 6.99 & pH 6.99 & $\mathbf{3 6 . 4 0}$ & $\mathbf{2 . 8 6}$ & $\mathbf{4 . 2 1}$ & $\mathbf{7 . 4 5}$ & $\mathbf{1 . 7 8}$ & 0.65 \\
\hline pH 8.5 & pH 8.5 & $\mathbf{1 5 2 . 4 5}$ & $\mathbf{2 . 6 7}$ & $\mathbf{1 5 . 0 7}$ & $\mathbf{1 6 . 2 3}$ & $\mathbf{5 . 9 4}$ & $\mathbf{2 . 4 3}$
\end{tabular}

After incubation with HA

\begin{tabular}{l|l|r|l|l|r|l|l}
\hline pH 5.55 & pH 5.32 & $\mathbf{2 . 6 0}$ & 0.68 & 0.29 & 0.99 & 0.13 & 0.05 \\
\hline pH 6.99 & pH 6.85 & $\mathbf{2 6 . 2 0}$ & $\mathbf{2 . 2 7}$ & $\mathbf{2 . 9 9}$ & $\mathbf{5 . 6 7}$ & $\mathbf{1 . 2 7}$ & 0.46 \\
\hline pH 8.5 & pH 7.89 & $\mathbf{7 4 . 9 6}$ & $\mathbf{2 . 4 3}$ & $\mathbf{7 . 8 1}$ & $\mathbf{1 0 . 5 2}$ & $\mathbf{3 . 1 7}$ & $\mathbf{1 . 2 4}$ \\
\hline
\end{tabular}

After incubation with saliva-coated HA

\begin{tabular}{l|l|c|l|l|l|l|l}
\hline pH 5.55 & pH 5.55 & $\mathbf{3 . 8 9}$ & 0.87 & 0.44 & 1.36 & 0.20 & 0.07 \\
\hline pH 6.99 & pH 6.88 & $\mathbf{2 6 . 9 0}$ & $\mathbf{2 . 2 5}$ & $\mathbf{3 . 0 6}$ & $\mathbf{5 . 7 4}$ & $\mathbf{1 . 3 0}$ & 0.47 \\
\hline pH 8.5 & pH 8.04 & $\mathbf{8 6 . 0 6}$ & $\mathbf{2 . 3 8}$ & $\mathbf{8 . 8 1}$ & $\mathbf{1 1 . 2 8}$ & $\mathbf{3 . 5 5}$ & $\mathbf{1 . 4 1}$ \\
\hline B & $\begin{array}{l}\text { Unbound fraction: calcium and phosphate in } 0.2 \% \\
\text { peptide complex }\end{array}$ & CPCP not associated with \\
& \multicolumn{7}{|c}{ Mineral } \\
\hline & HA & DCPD & TCP & OCP & Acid ACP & Basic ACP \\
\hline Original pH & Final pH & $\mathbf{3 . 7 8}$ & 0.85 & 0.43 & 1.32 & 0.19 & 0.07 \\
\hline pH 5.55 & pH 5.55 & $\mathbf{1 8 . 4 8}$ & $\mathbf{1 . 3 5}$ & $\mathbf{1 . 9 7}$ & $\mathbf{3 . 8 3}$ & 0.83 & 0.31 \\
\hline pH 6.99 & pH 6.99 & $\mathbf{3 1 . 8 0}$ & 0.50 & $\mathbf{2 . 6 3}$ & $\mathbf{3 . 5 9}$ & $\mathbf{1 . 0 4}$ & 0.45 \\
\hline pH 8.5 & pH 8.5 &
\end{tabular}

After incubation with HA

\begin{tabular}{l|l|r|l|l|r|l|l}
\hline pH 5.55 & pH 5.32 & $\mathbf{2 . 5 0}$ & 0.65 & 0.28 & 0.95 & 0.13 & 0.04 \\
\hline pH 6.99 & pH 6.85 & $\mathbf{1 6 . 6 2}$ & $\mathbf{1 . 3 7}$ & $\mathbf{1 . 7 9 5}$ & $\mathbf{3 . 6 3 7}$ & 0.76 & 0.28 \\
\hline pH 8.5 & pH 7.89 & $\mathbf{2 3 . 8 1}$ & 0.73 & $\mathbf{2 . 1 9}$ & $\mathbf{3 . 5 1 4}$ & 0.89 & 0.36 \\
\hline
\end{tabular}

After incubation with saliva-coated HA

\begin{tabular}{l|l|r|l|l|r|l|l}
\hline pH 5.55 & pH 5.55 & $\mathbf{3 . 7 6}$ & 0.836 & 0.427 & $\mathbf{1 . 3 0 9}$ & 0.19 & 0.07 \\
\hline pH 6.99 & pH 6.88 & $\mathbf{1 6 . 9 1}$ & $\mathbf{1 . 3 4}$ & $\mathbf{1 . 8 2}$ & $\mathbf{3 . 6 4}$ & 0.77 & 0.29 \\
\hline pH 8.5 & pH 8.04 & $\mathbf{2 6 . 5 6}$ & 0.68 & $\mathbf{2 . 3 8}$ & $\mathbf{3 . 6 4}$ & 0.96 & 0.40 \\
\hline
\end{tabular}

(A) Calcium and phosphate in total fraction; (B) calcium and phosphate in unbound fraction. Values in bold indicate saturation with respect to the phase

\subsubsection{SEM Reveals Images of Non-crystalline Morphology for CPP-ACP Complexes}

Preliminary SEM images of 5\% CPP-ACP solution show areas with a non-crystalline morphology expected for colloidal complexes (Fig. 24.4). 


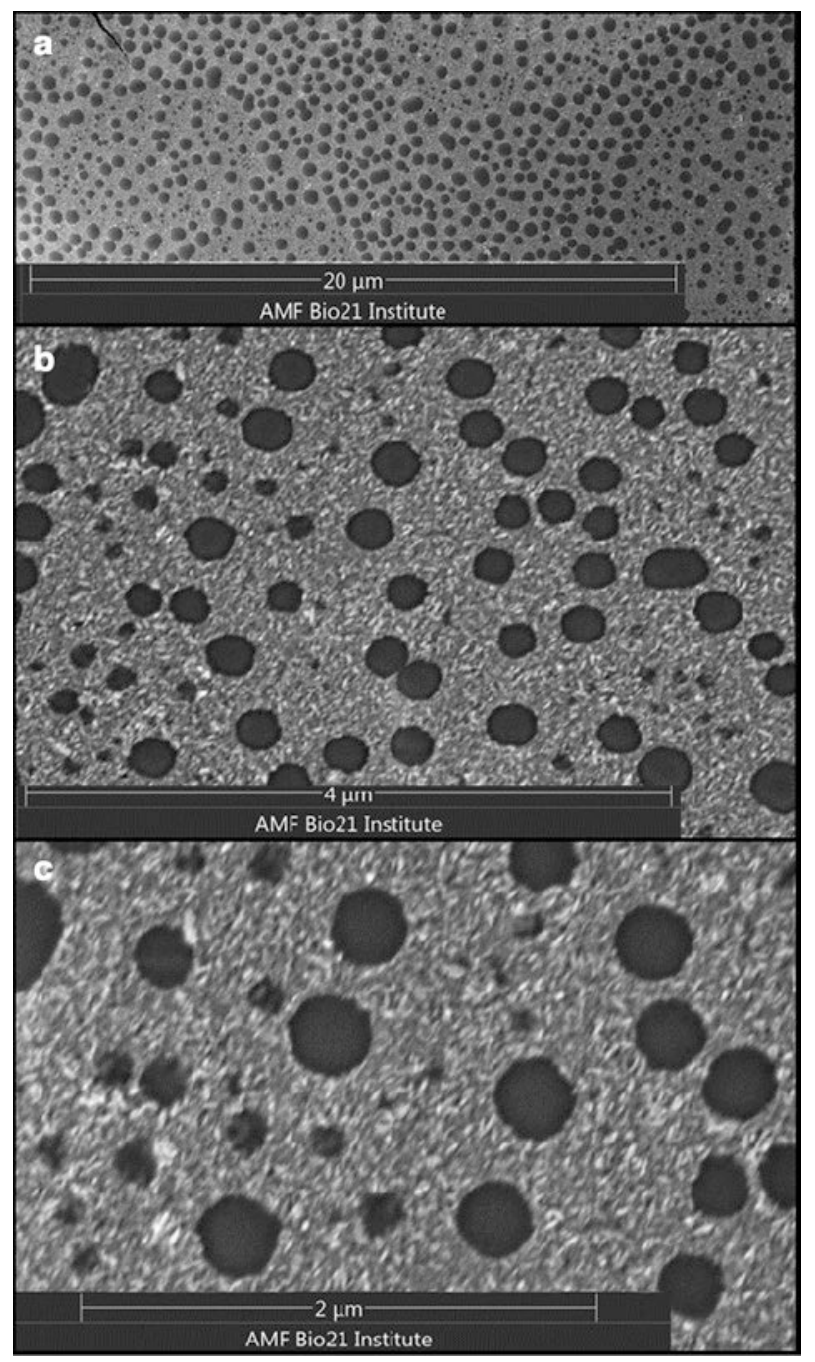

Fig. 24.4 SEM images of CPP-ACP at increasing magnification, taken using a T1 (BSE) detector with beam deceleration in a Teneo VS Instrument (FEI) for enhanced surface details. Two $\mu 1$ of 5\% CPP-ACP, pH 7.24, was deposited onto a silicon substrate on an aluminium stub, and the excess liquid was removed after $1 \mathrm{~min}$. CPP appeared to have formed spherical particles that were surrounded by ACP. Landing energy, $1 \mathrm{keV}$; stage bias, $-2 \mathrm{kV}$ 


\subsection{Discussion}

The observed biomimicry of CPP that spontaneously self-assemble at $\mathrm{pH} 9$ forming complexes with calcium phosphate ions offers a functional advantage for the stable storage and delivery of mineral ions. This paper describes interactions of the peptide and mineral components of this delivery vehicle with enamel substitute HA.

In addition to the adsorption of purified casein phosphopeptides onto uncoated HA, these studies confirmed that casein phosphopeptides also adsorbed onto the saliva-coated HA being a mimic of the enamel salivary pellicle. Previously, we have demonstrated that the casein phosphopeptides interact with salivary proteins including those forming the enamel pellicle (Huq et al. 2016). Collectively, these studies confirm that during topical application of a formulation with CPP-ACP complexes, the peptides are not simply inert carriers of mineral. Instead, they are capable of adsorbing to the crystalline enamel surface that has been recently brushed as well as interacting with the salivary pellicle that forms on the enamel surface.

Since HA is not an inert material, the molecular events at the HA surface are of interest. The casein phosphopeptides elicited an adsorption-mediated release of calcium ions from HA into the solution. This is consistent with previous studies documenting the release of ions from HA during adsorption of proteins and amino acids (Misra 1997; Pearce 1981). In contrast when HA was introduced to the peptideACP complexes in solution, there was a net loss of calcium and phosphate ions from the solution indicating a net gain of calcium and phosphate ions by the crystalline HA. These studies confirm that the mineral ions of the amorphous phase of ACP that is stabilised by the peptides transfer to the crystalline HA monotonically with increasing $\mathrm{pH}$. Furthermore, during topical application, the dissociation of the CPPACP complexes and the subsequent migration of ions to the enamel surface are not hindered by the enamel salivary pellicle.

In conclusion, within the oral environment, the enamel remineralisation process involves a complex interplay between the peptide and mineral ions of the CPP-ACP delivery vehicle and the tooth enamel mineral with its salivary pellicle.

Acknowledgements We would like to thank Mr. Roger Curtain from the Bio21 Advanced Microscopy Facility, the University of Melbourne for his assistance in SEM imaging.

\section{References}

Cochrane NJ, Cai F, Huq NL, Burrow MF, Reynolds EC (2010) New approaches to enhanced remineralization of tooth enamel. J Dent Res 89:1187-1197

Cross KJ, Huq NL, Palamara JE, Perich JW, Reynolds EC (2005) Physicochemical characterization of casein phosphopeptide-amorphous calcium phosphate nanocomplexes. J Biol Chem 280:15362-15369

Cross KJ, Huq NL, Reynolds EC (2016) Casein phosphopeptide-amorphous calcium phosphate nanocomplexes: a structural model. Biochemistry 55:4316-4325 
Dashper SG, Catmull DV, Liu SW, Myroforidis H, Zalizniak I, Palamara JE, Huq NL, Reynolds EC (2016) Casein phosphopeptide-amorphous calcium phosphate reduces streptococcus mutans biofilm development on glass ionomer cement and disrupts established biofilms. PLoS One 11:e0162322

Huq NL, Myroforidis H, Cross KJ, Stanton DP, Veith PD, Ward BR, Reynolds EC (2016) The interactions of CPP-ACP with saliva. Int J Mol Sci 17:915

Misra DN (1997) Interaction of ortho-phospho-l-serine with hydroxyapatite: formation of a surface complex. J Colloid Interface Sci 194:249-255

Pearce EI (1981) Ion displacement following the adsorption of anionic macromolecules on hydroxyapatite. Calcif Tissue Int 33:395-402

Reynolds EC, Cain CJ, Webber FL, Black CL, Riley PF, Johnson IH, Perich JW (1995) Anticariogenicity of calcium phosphate complexes of tryptic casein phosphopeptides in the rat. J Dent Res 74:1272-1279

Robinson C, Shore RC, Brookes SJ, Strafford S, Wood SR, Kirkham J (2000) The chemistry of enamel caries. Crit Rev Oral Biol Med 11:481-495

Open Access This chapter is licensed under the terms of the Creative Commons Attribution 4.0 International License (http://creativecommons.org/licenses/by/4.0/), which permits use, sharing, adaptation, distribution and reproduction in any medium or format, as long as you give appropriate credit to the original author(s) and the source, provide a link to the Creative Commons license and indicate if changes were made.

The images or other third party material in this chapter are included in the chapter's Creative Commons license, unless indicated otherwise in a credit line to the material. If material is not included in the chapter's Creative Commons license and your intended use is not permitted by statutory regulation or exceeds the permitted use, you will need to obtain permission directly from the copyright holder. 